\title{
Tutorial on the emergence of local substructure failures in the railway track structure and their renewal with existing and new methodologies
}

\author{
B. Eller ${ }^{1}$, Sz. Fischer ${ }^{1, *}$ \\ ${ }^{1}$ Széchenyi István University, Department of Transport Infrastructure and \\ Water Resources Engineering \\ Egyetem tér 1., 9026 Győr, Hungary \\ *e-mail: fischersz@sze.hu
}

Submitted: 18/09/2020; Accepted: 27/10/2020; Available online: 04/12/2020

Abstract The construction and maintenance of a railway track is an expensive process. Therefore, nowadays, except for advanced countries, considerable attention must be paid to apply the optimal maintenance of railway lines. In Hungary, until 2020 nearly 11\% of railway tracks were renewed and rehabilitated from EU support, which means millions of Euros, i.e. billions of Hungarian Forints. It also follows from the support that planned preventive maintenance works must be performed on the renewed and rehabilitated lines. On the other hand, it takes away significant costs from the non-renewed (non-rehabilitated) lines maintenance works, but naturally, less money does not mean less failures, so cost-effective technologies are needed. A segment of maintenance is the local substructure problem(s). In this article, this segment will be mentioned from the development of the failures, through the applied technologies, to the possible new solutions like injection and the using of geosynthetic cementitious composite mats (so called GCCMs).

Keywords: substructure; local failure; protection layer; injection; concrete canvas 


\section{Introduction}

The deterioration of the railway (track) is only to be shown with a genuinely complex correlation. The pressure that the loads of the railway generates is divided amongst the elements until it reaches a lower level exerted on the substructure than on the rails, for instance (Fig. 1). In conclusion, this load transfer does not inflict serious obsolescence; however, the dynamically arriving loads do. The dynamic loads can cause a slight bend even on high quality railways, both in the railway track and at its joints. That is what the saying is for: there is no such perfect track because there can be occurring problems in all kind of aspects. As the elements in the system of the railway's structure are correlating with each other, some of them even contribute in the initiation of some of its fellow's obsolescence, hence it can be seen at the term 'obsolescence' as a self-initiating exponential procedure. The load transfer can be seen in Figure 1. [1, 2].

One of the railway's cardinal spots is the substructure. When a problem occurs with the substructure it might not be only because of the load (from the vehicles and dead load), but environmental effects, like the consistence of the soil can affect it as well. Either the not properly constructed, or not of proper, materials-built support can cause some reoccurring problems in the long term and also maintaining it in some cases is nearly impossible. That is why solutions are needed, that can increase the longevity of the whole track by opting to use long lasting and appropriate supports. Problems that are only appearing at one particular spot in the railway and can be traced back to the substructure are called local substructural problems [3].

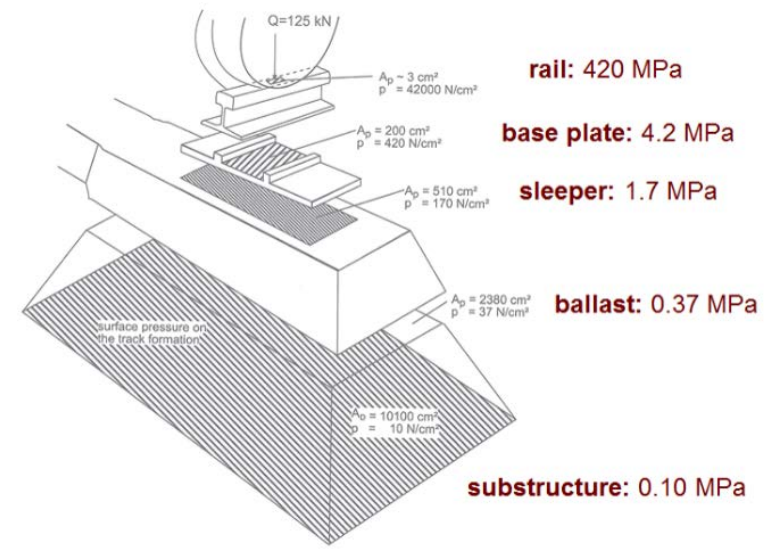

Figure 1. The load distribution in the railway superstructure based on [2] 


\section{Formation of local substructure failures}

Speed restrictions made by problems in the railway result in the need of more dragging force in order to reattain the original velocity. This extra energy expressed monetarily is many billion Hungarian Forints annually [4], in addition to the already extent problems that are already expensive. If they increase the axle load by 2 and a half tons the extra cost would be an additional $4.2 \%$ to the maintenance fee [5]. If the substructure does not have enough load capacity and proper soil mechanical features, then soil swap or installing a defensive layer is in need. Speaking of a local substructural problem, full interference depending on access might be expensive, let alone technical barriers.

\subsection{Questions of design}

Functions of the railway substructure's reinforcing layers [6]:

- $\quad$ securing load carrying base layer for the ballast (middle layer's main task),

- $\quad$ preventing frost effect in the track (frost protection layer's main task),

- $\quad$ load distribution in the subsoil,

- making sure that the rail and its other parts provide proper flexibility,

- $\quad$ avoiding the blending amongst the middle layers and the ballast with the lower weaker layers,

- $\quad$ avoiding the blending between the anti-freeze layer and the subsoil's material (filtering layer).

A properly constructed railway embankment provides homogeneous support for the railway superstructure.

At designing a substructure for a railway, the following aspects you should consider:

- axle load,

- design velocity,

- $\quad$ subsoil’s consistence, quality, etc.

Economically the substructure has to last at least 40 years and needs to be capable of going under maintenance any time. In Hungary, the planned nominal axle loads are mostly from $210 \mathrm{kN}$ through $225 \mathrm{kN}$, whereas in other countries it can go a lot higher, even up to $360 \mathrm{kN}$ in North and South America or $440 \mathrm{kN}$ in Australia [7].

Speaking of track system in the aspect of continuity there are traditionally joint and also gapless tracks (CWR track that means continuously welded rail tracks). In 
these cases, it is needed to create dilatative gaps accordingly to the laying rail temperature, so when it comes to colder weather the gap expands, which is succeeded by continuous dynamic additional effects towards the rails. Other solution would be a rail expansion device that is meant to operate the rail dilatation due to how its shape transforms when interacting with objects with a given rail temperature.

\subsection{Reasons of emergence}

Main reasons that contribute to the emergence of problems in the subgroup can be categorized into three classes [8]:

- $\quad$ loading factor (failures from deteriorated structure elements)

- features of the soil / and/or design / (poor quality, consistence of the soil),

- $\quad$ environmental factors (soil moisture content, soil temperature).

There are two types of load in the railway tracks:

- $\quad$ the dead load of the structure (so called static load),

- the dynamic load from the traffic/vehicle (static value + dynamic addition).

Although problems that may occur are divided into three groups, yet they appear together often, therefore every local substructural error demand to be taken seriously when investigated.

\subsubsection{Loading factors}

The dead load causes less amount of complications than the dynamic effects, however, when the filling has not been properly built or designed, it may inflict serious damage regarding stability or shearing. The dynamically emerging traffic load is a repeating, cyclic type of load. The effects of the static and dynamic loads differ on the lower layers, even if the axle load is the same $[8,9]$.

When it comes to traditional railway tracks where the joints are situated 21-24 meters apart from each other the amount of problems by dynamic collisions are occurring more often, however, the speed limit on these tracks are a lot more strict (in Hungary it is $80 \mathrm{~km} / \mathrm{h}$ top). These dynamic collisions may result in some loose fastenings, a sunken substructure and even the ballast wears down a lot faster. On top of those faults/errors, there are a lot more in addition: the end of the rails can bend down. In order to recover their original shapes a particular technology has to 
be used. The errors are situated according to the locations of the gaps (standard is 1 per every 24 meters) $[1,10]$.

Hypothetically, it is impossible that there would be a load caused by similar dynamic collisions in the tracks due to the welded rails placed in them. Nowadays there have been a couple of welding methods in use when it comes to constructing major railways [2]:

- $\quad$ flash butt welding (either in a welding plant or by a moving machine),

- aluminothermic welding (thermit welding or AT welding).

This is claimed to be true hypothetically, however, in practice, especially on old weldings the wear can be faster (an outcrop emerges) than on the surface of the rails. The main reason for that is that the AT (aluminothermic) welding is about the correspondence of "three different type of materials" (the two rails and the welding material), and the steel that supports the joints wears down faster than the steel that makes the rails because the former one's features are weaker. There is no publication about that, so what the authors asserted is only based on their experience. The reason why it is important to emphasize that problem is that when short-railed tracks are constructed to CWR tracks nowadays it is sure that these weldings are 24 (or 21) meters apart from each other. The outcropped weldings cause smaller but similar problems than the weldings on traditional railways. The collision is smaller, even though, these types of problems mean larger dynamic addition load at higher track velocity.

The deflection, the substructural deformations at the supporting tracks with different stiffness occur either where the bridge and the railway tracks meet (Fig. 2), or where the tunnel and the railway track join each other are making another focal spot. The stiffness of the support by the bridge abutment suddenly changes which results in the moving train accelerating vertically that generates addition-of-use in the tracks. These problems can cause serious distortion in the track geometry on tracks that were not properly constructed or are already deteriorated, additionally mudding may occur when it does not have appropriate drainage. Therefore, the main problem is from geotechnical/loading and either from structural or design causes. The primary reason why temporary tracks are needed is to reduce travel time that increases the design velocity, which results in the tendency of addition-of-use and obsolescence. $[11,12]$ The problem is mainly depending on the soil's factor, however, it is mainly 
because of the addition-of use by the change of stiffness, therefore it goes to the loading factors when classifying.

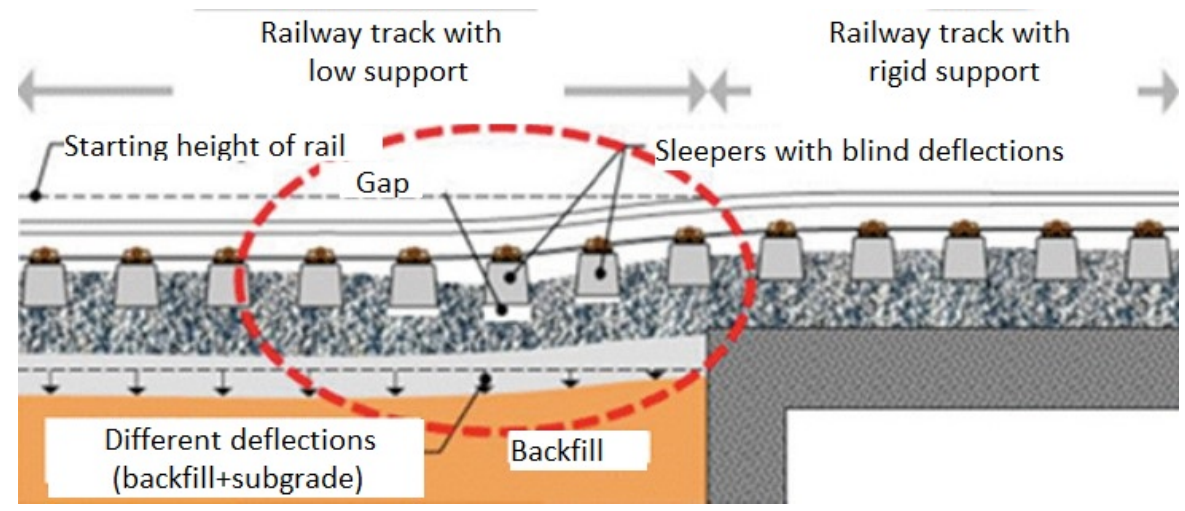

Figure 2. Track failure in the track-bridge transition zone based on [12]

\subsection{2. $\quad$ The consistence of the substructural embankment $=$ Soil factors}

There were numerous publications conceived regarding the consistence of the embankment that have an elaborate description on the principles of design, construction, as well as maintenance in connection with geotechnics $[13,14,15,16]$. An important thing in the railway is the proper support that can be achieved with a substructure that meets the requirements in both the aspects of compressibility and load capacity. Even if these factors are given the work is not entirely done because the drainage is still to be emphasized, moreover, the layer separation mustn't be left out either.

When a problem occurs, the soil factor means that it does not have adequate mechanical characteristics, like fine clay or mud. The change of moisture content (water content) in these types of soils usually results in expansion, so they would be a poor solution when it comes to load capacity. On top of that the previously mentioned loading factor by weak soils is significantly important because blending and compression are expectable on the surface when it is under dynamic load in such moisture content. That is why it is emphasized to apply either granular soils or complementary layers because they secure the evaporation and the drainage of the water. 
The embankment's width is another factor in restricting the ballast's deformation under the vehicles' loads throughout its lifespan. In order to save money, these embankments are constructed relatively narrow with an inappropriate ratio of 1:1.5 sloping. On the other hand, there are embankments, which were constructed decades ago with a paving of lateral support that has already been either eroded, or lost. This might cause improper lateral support and excessive permanent distortion in the structure of the embankment [6]. In Hungary there has been numerous amount of precedents, where the sloping of the embankment eroded after installing a complementary layer, that later got fragmented vertically due to support deficiency. Therefore, the width of the paving decreased or got lost [17].

\subsubsection{Environmental factors}

As far as the ballast fragmented, got stained or due to substructural deformation the water's drainage from the surface of the substructure is not secured (Fig. 3), the muddy residue of precipitation pumps up as a result of each and every dynamic force. The soil particles are still staining the ballast and keep the water back from flowing (Fig. 4.) [18].

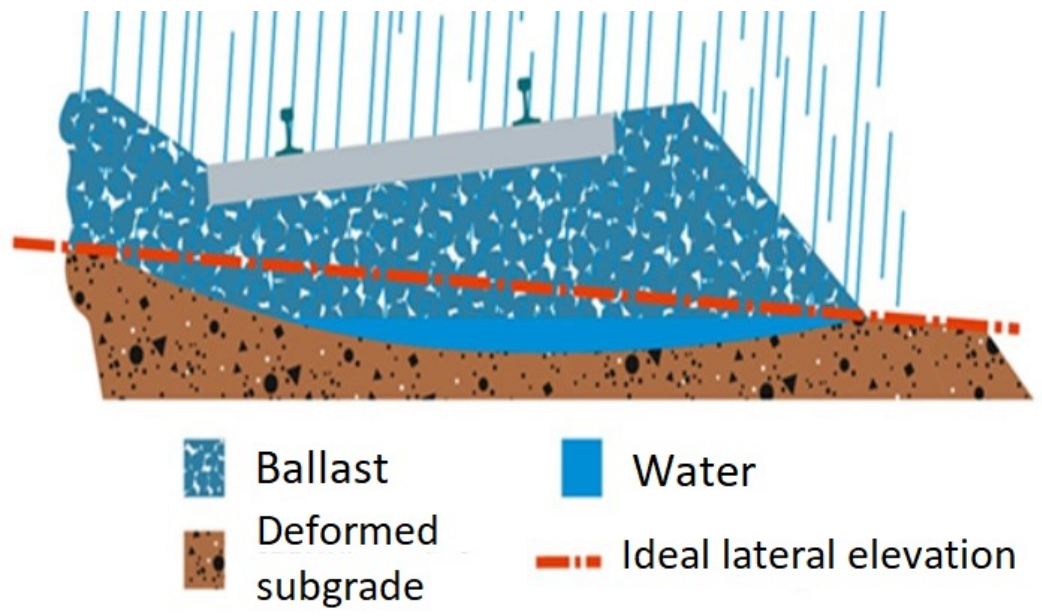

Figure 3. Dewatering is not working on the deflected substructure based on [18] 


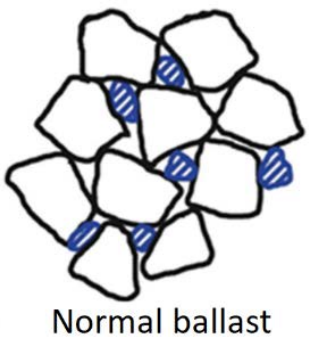

Normal ballast

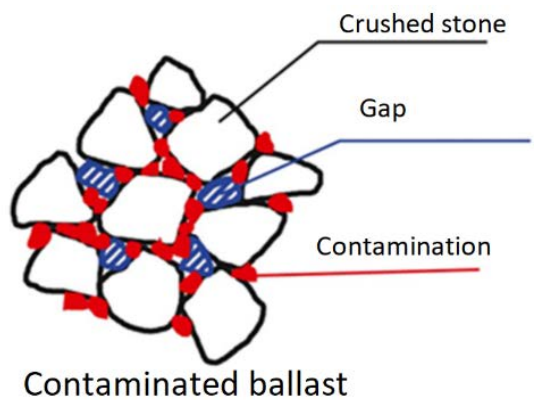

Contaminated ballast

Figure 4. The contamination of the ballast based on [18]

As the soil and the ballast settle, even a couple meter deep-water pocket can emerge that is induced by the precipitation penetrating from above. The water pocket is officially defined as embankment range or deterioration form in which the stone material of the ballast and the substructure are settling due to the dynamic and/or hydraulic procedures [3]. The water pocket itself is a typical locally emerging problem, that's removal is really expensive. In the aspect of drainage, it does not matter how clear the ditch is next to the railway when it is not able to exit the railway structure as it can be seen in the Fig. 5 .

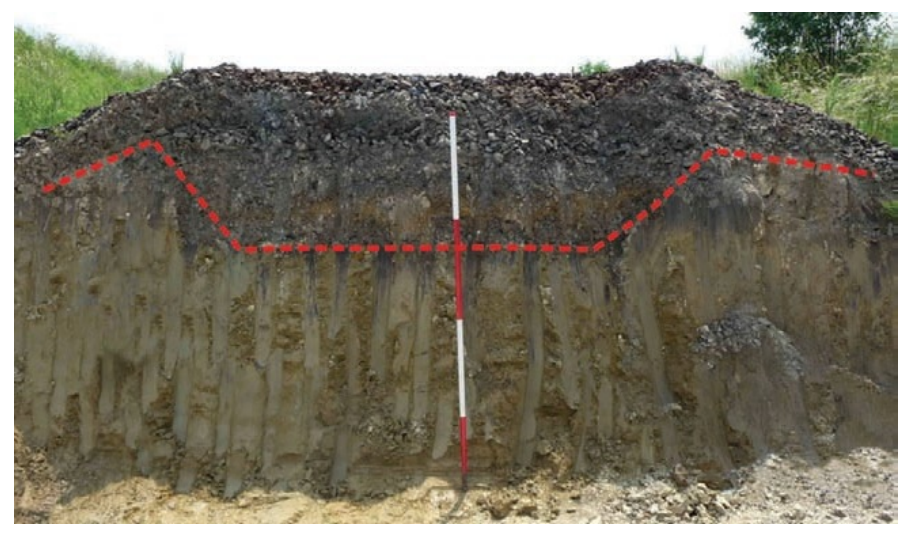

Figure 5. Water pocket in the substructure in initial stage [19]

Apparently, due to the dynamic addition loads, the ballast particles get pushed in and settle with the embankment material that was softened by precipitation and a temporary streak between the ballast and the embankment emerges where the 
settlement of the materials provides a descending support in practice. In a case like this, layer separating complementary layers are to be applied.

The particles in the ballast are getting indented in a particular manner, because the position of the ballast doesn't cover the substructural embankment entirely, so the transferred load shares the mass through less amount of particles than the area of the ballast would. This is justified by the research made on the subconcrete's position [20].

Other local problem opportunity in addition is a more seldom occurring, even though there were numerous cases of substructural indentions of animal origin. Some mammals carve out tunnels in the embankment that later on collapses and causes lots of distortion in the tracks (Fig. 6.), which can only be repaired by spending a lot of money by having someone fix it with a special repairing method [21]. This type of repair is elaborated in Chapter 4.2.

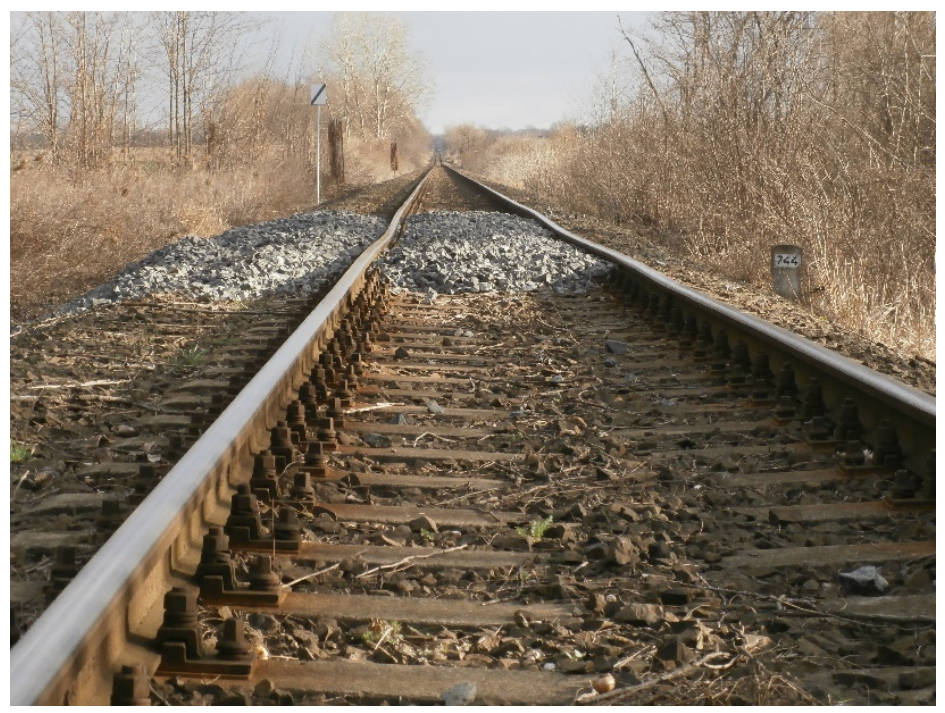

Figure 6. Local substructure fault due to cavity rupture [21] 


\section{Diagnostics of the substructure failures}

According to the new order D.5 by MÁV Zrt., the registration of local substructural problems is to be done at the annual walk-ins, while the tracing has to be constantly in progress [22]. The tracing and the evaluation is to be completed when doing the observing and the examination of subsidence under loads measured by trackgeometry.

While doing track diagnostics, where small frequented, great amplitude waves emerge at a point are referring to the interruption of the substructure. Depending on this when examining diagrams these problems [23].

Thorough analysis can be done from the deflections moving spread. Those are local problems regarding railway diagnostics when among the measured railway diagnostic parameters, in a particular moment/point either of those exceeds the prescribed measuring range. A local substructural problem can be inferred when the moving standard deviation of the draft parameter differs from the surrounding values based on a graph and to a significant extent during the track diagnostic measurement. The subsidence moving spread is to be evaluated by in a mathematical way [24]. Efforts have already been made to propose the classification of value into size limits [25], but no formal size limits have been set until the writing of this article. However, as the authors wrote earlier, these procedures can only be used to infer the origin of the substructural problem. The more precise definition of the problem can be done by excavations, trenching and soil mechanical drilling.

Another accurate method for concluding is the usage of georadar (GPR-Ground Penetrating Radar). Their application has been thoroughly investigated in [26] and [27] literatures, among others. The electromagnetic shortwaves emitted by the georadar are reflected from the different dielectric layers, and thus revealing the thickness and location of the given layers (Fig. 7). The soils' dielectric constants of different qualities are determined by moisture content, soil density and structure. A further development of this became a radar-detectable geotextile to which a $20 \mathrm{~cm}$ wide aluminum sensor was attached. This got integrated into the railway track structure, provides better reflection of the electromagnetic signals and makes any structural deformations more detectable. The method assists with georadar tests performed in subsequent operations and provides long-term controllability [28]. 

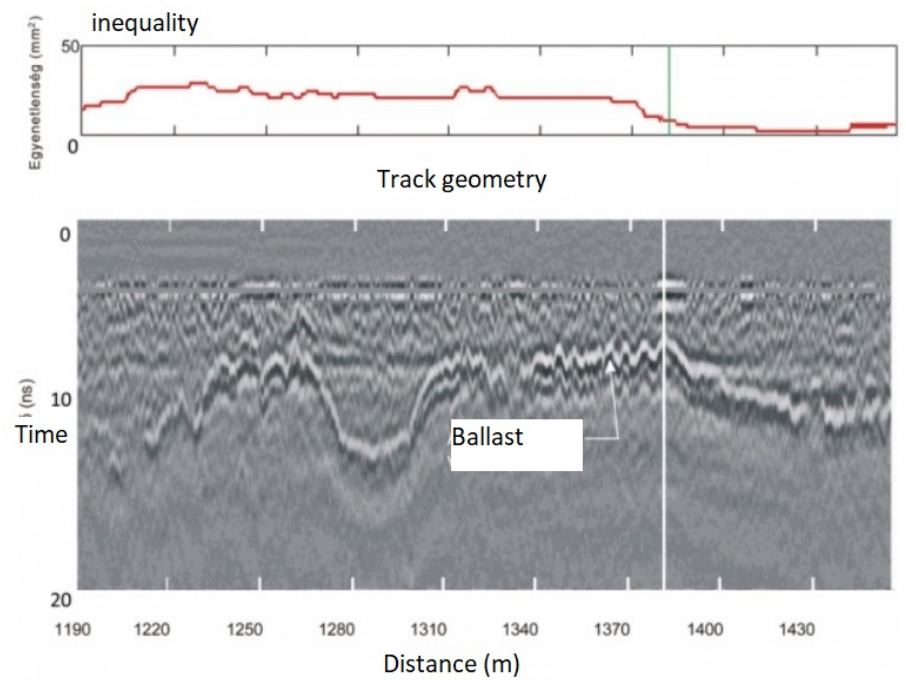

Figure 7. Evaluation of the georadar's measurement based on [28]

\section{The possible renewing technologies of the local substructure failures}

The authors have already written in the previous part of the article that the examination of each local substructural problem's location requires a complex task. This is really important to emphasize because it is common for certain problems to be corrected simply by ballast screening and possible trenching, and then the problem returns in several cases. Geogrid and geotextile will be installed at the same time as ballast screening. The complex test should therefore include the inspection of the drainage facilities because if the rainwater receiver is not available, the drainage will not be complete. Another problem is if the screened material is deposited directly next to the track, as water on the already contaminated material either does not flow and can leak towards the track or flow back towards the track.

\subsection{Renewing by mostly used technologies}

Usually, a multifunctional protective layer is built in between the ballast and the substructure crown (upper plane of the embankment). It is made up of natural and / 
or artificial materials. The applied technology must be determined depending on the needed functions to be performed and the technical parameters of the used materials [9].

Generally, the following solutions are used to reinforce the structure or substructure of a railway track [3]:

- CGM1, CGM2, sandy gravel, etc .;

- soil stabilization,

- geosynthetics (geogrid, geotextile, geocomposite, etc.),

- asphalt protection layer,

- XPS extruded polystyrene slabs.

\subsubsection{Coarse grained mixture (CGM)}

By constructing a granular layer, the problem can be improved in the medium term. Mixtures of CGM1 and CGM2 have been transposed from the German Railway Construction Directive Ril.836 [29] into Hungarian standards [3]. The CGM1 layer is quasi-water sealing, so it can provide a suitable solution with proper drainage. The CGM2 layer functions as a load-bearing layer similarly to the CGM1 but acts as a water-permeable layer due to its particle size distribution [3]. This ability is also true for sandy gravel with the required particle size distribution. The efficiency of the latter materials in the case of water-related problems is questionable, other materials with a layer-separating role (e.g. geotextiles) can be said to be obligatory.

However, this requires a machine such as PM1000-URM [30], which is able to build in the granular layer and perform the screening process in one time. From an economic point of view, it is questionable whether the application of such a technology is necessary if the substructure faults occur only locally within just over a few hundred meters.

\subsubsection{Stabilizations}

The stabilization of the subgrade on the old embankment can be done with different binders and (partly) different technologies. The applicable materials depend on the soil's consistence, that can be lime, cement or chemical stabilization, and without any binder, they are so called mechanical stabilization.

For the mentioned main problem, none of the listed stabilization solutions are adequate, because there are many physically and approach aspects which needs 
higher space and more technological time. Due to this, that would not be an economical and good solution to fix a local failure.

Another type of stabilization is the application of glue material in the ballast. In [31] improvement was shown at the bridge ends in terms of reduced track settlements and the stability of track surface geometry. In [32] more investigations and results were published. On the other hand, the glued ballast does not solve fully the drainage problems, thus, it is not a good solution for renewing local substructure failures.

\subsubsection{Geosynthetics}

From the aspect of railway construction, the following geosynthetics are used [3]:

- geotextile,

- geogrid,

- geocomposite,

- geomembrane.

The primary aspect of renewing local substructure failures is the good drainage, the full covering of a water-sensitive embankment, and the prevention of further mixing. If a geotextile is laid on a deformed surface, it will pick up the plane of the surface due to the ballast. In this case, if there is no adequate "cross-slope" on the surface, the water will seep through the geotextile and remain in the substructure in the same way.

By using the geogrid, the load bearing capacity is increased, the shear resistance in the lower part of the ballast increases and making the ballast "beam" less sensitive to deflection. However, at this solution the drainage is not solved. As a result, the "movement" (settlement) of the substructure is continuous because of the change of volume due to moisture. So highly probable, the base length of the deflection is extended in longitudinal direction.

For the reasons described above, laying a geocomposite (geogrid + geotextile) may be a sufficient solution, as it bears beneficial effects together. However, on an especially weak section, this provides only a short-term solution, because the dewatering does not work well.

The application of geomembrane can be a suitable solution as complete water exclusion can be achieved by laying it on the plane of the already reinforced substructure. By doing this, the moisture content of the water-sensitive substructure 
can only be affected by the capillary water pressure. However, it should also be noted that in the case of a substructure with inadequate load capacity, if a deflection occurs, it restrains the water as a "trough".

In conclusion, geosynthetics that can be incorporated during ballast screening can provide an economically efficient solution, but a long-term solution can only be achieved by installing geomembranes that seal the substructure, and thus preventing the infiltration of precipitation and the associated volume change, siltation and crushing. However, for the reasons mentioned earlier, this would only be a suitable solution if the load capacity of the substructure is also appropriate.

\subsubsection{Asphalt protection layer}

The asphalt protection layer could be an excellent solution, because its separation function is perfect, while it provides significant increase in load bearing capacity. In many countries, the technology is applied in both high-speed rail traffic and on lines where higher axle loads are required due to significant freight traffic [33, 34].

However, similar to stabilizations, there are physical conditions in the approach that would not be an economical solution to renew a local failure and could only be built in inaccessible places by manual installation and compaction.

\subsubsection{XPS polystyrene slabs}

The advantage of extruded polystyrene slabs is that these are a highly flexible material with thermal insulation properties. It has high compressive and flexural strength. Its water uptake is negligible, which also means that its resistance to freezethaw cycle changes is appropriate. Aging and dry rot are not to be expected. The low dead weight and easy machinability make it suitable for use to protect the railway substructure. Experiences have shown that by modifying the screening machine during the renewing, the sandy gravel layers can be neglected, but damage can happen while laying [9]. It has been used in a few places in Hungary so far (railway line 40. between Szentlörinc and Pécs; Budapest tramway line 1), but the experiences were adequate [2].

If polystyrene slabs were installed, the falling rainwater would be drained until there is no defect in the substructure. On the other hand, easy to imagine that the slabs could bend and break locally, then the falling rainwater collects in one smaller territory in the superstructure and the substructure is soaked at one point. For these 
reasons, their installation would only be ideal if a granular layer were to be built in before laying, as a reinforcement of the railway track.

\subsection{Possible new solutions}

In the case of local substructure faults, optimal solutions are needed, which provides drainage on the substructure crown, give reinforcing effect, and are easy to build in. None of the listed technologies guarantee these requirements. Therefore, the application and experimentation of new technologies is justified.

\subsubsection{Injection}

Two types of injection methods are applied in the construction industry, "cement milk” injection and polyurethane injection. In the case of both technologies, the approach to the construction site is less of a problem, the injected substructure is sufficiently strengthened, and the drainage is also solved.

The "cement milk" injection solution is also used in China, where substructure of high-speed railways is the weak and the substructure and its foundation are strengthened with it. [35,36] The solution has also been applied in Hungary several times, including at the mentioned animal substructure fault of main line 41 in chapter 2.3.3. [21], at the reconstruction of the main line 30 at Dél-Balaton (South-Balaton) section to strengthen the backfilling of a bridge, and at the railway line 36 to locally strengthen some sections. Based on short-term experience, the solutions proved to be appropriate. The disadvantage of the technology is that the amount of the required material is unpredictable. On the other hand, rigid points can be developed, which can be followed by failures at the transition sections, like at the already explained.

The injection of polyurethane foam into the railway substructure has been studied in [37], and the injection of ballast has been discussed inter alia in [38] (Fig. 8). The theory of the installation is the same as for the injection of "cement milk", but while the "cement milk" solidifies, the polyurethane foam (RPF) expands, thus filling the pores, narrow gaps.

Therefore, the injection reinforcement causes a long-term increase in load capacity, improves the properties of the substructure, and fills the pores thus reducing the water absorption capacity/possibility of the railway substructure material. The solution could be cost-effective and would provide an additional tool for railway maintenance by demonstrating its impact. 


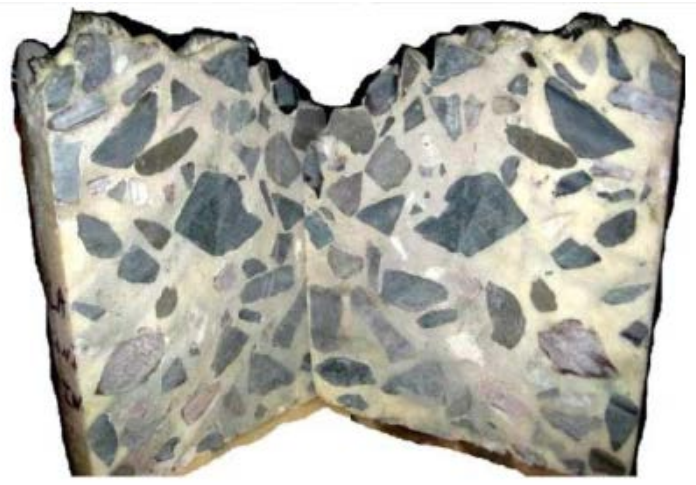

Figure 8. Injectioned ballast bed sample [38]

Due to the disadvantages of the technology, it may be risky to install on higher speed railway lines, but on those inferior railway lines where the problem is serious, but because of the underutilization and other reasons, it would be a waste of money to spend, these solutions could be good maintenance options.

\subsubsection{Geosynthetic cementitious composite mats (GCCMs)}

This technology has entered into the construction industry in the last decade. By building in it, mainly layer separation and drainage problems can be solved. These materials are cement impregnated fabrics that would harden when they are being hydrated with water, thus, providing high rigidity and strength [39,40]. GCCM is commonly applied as an alternative solution of shotcrete [40]. Several variants were invented, however, the most effective solution proved to be a cementitious material impregnated between two layers of geotextile, thus forming a "sandwich" structure. The upper geotextile is non-woven, while the lower is of the woven type. Its installation does not require serious expertise, and transportation to difficult places is also easier.

Among the mentioned products, one of the most promising one is Concrete Canvas (CC) (Fig. 9). The upper fibrous fabric and the lower PVC waterproofing layer are connected by a 3D fiber matrix, and a special cement mixture is filled between the two layers [41]. According to official data scripts, the compressive strength of the hardened concrete slab is $80 \mathrm{MPa}$ after a setting time of 28 days. Its $80 \%$ (but at least $50 \mathrm{MPa}$ ) is reached 24 hours after hydration. After bonding, the fiber structure 
strengthens the concrete, avoiding cracking. Its lifespan is roughly 50 years [42]. Its effectiveness has been presented in several case studies [41].

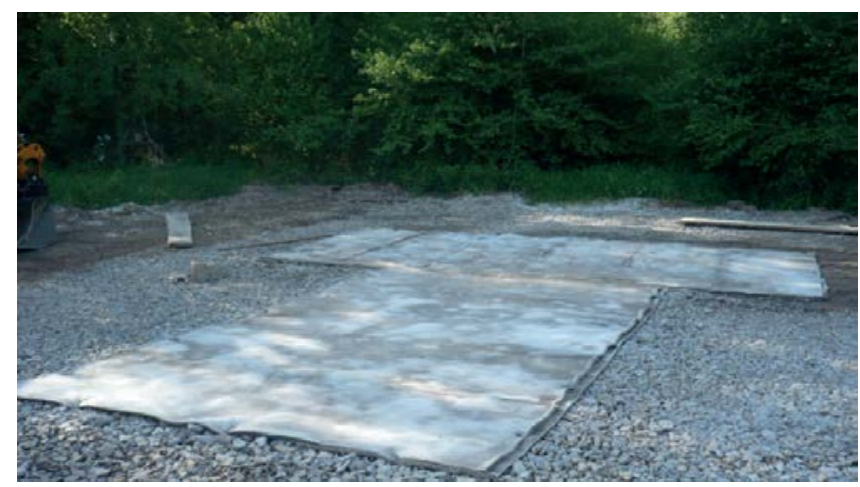

Figure 9. Installing of CC for experimental mobile building foundation [43]

The material can be built in easier by hand or machine when a local substructure failure is being renewed, because the material is delivered in scrolled up formation like geosynthetics, so the screening machine can pull it in under the ballast bed. Based on the authors' theory, CC conforms to the bending (settlement) and deformations of the terrain (Fig. 10). If the cement in the layer is bonded only after the ballast has been screened, the rigid layer will be deformed, while suiting to the shape of the ballast bed particles, to some extent. Due to this, it can be assumed that in this way, compared to the application of geogrids, some amount of "interlocking" effect is created. Thanks to this, the internal shear resistance of the ballast increases at the lower part of the thickness. [4, 44] 


\section{Designed ideal case}

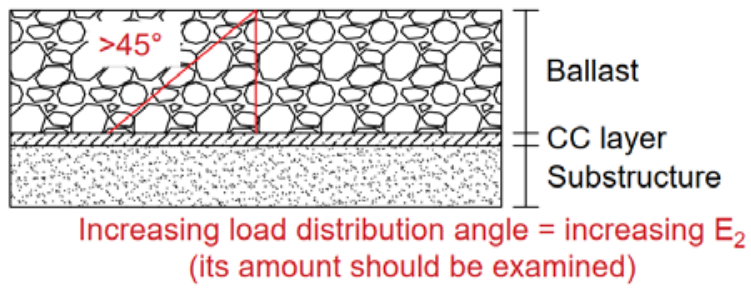

\section{Real case}

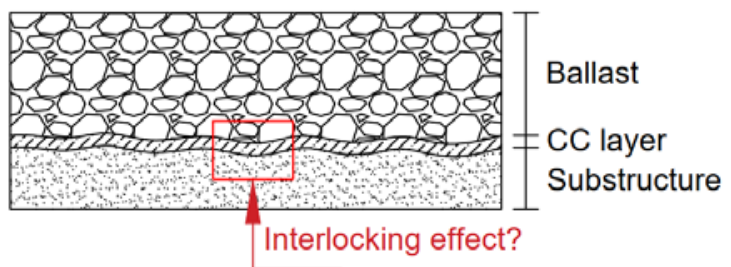

Figure 10. Laying of CC on the substructure crown while ballast screening [44]

To connect the main topic, with usage of the cementitious geosynthetic composite mats the local substructure failures can be improved with good chance. Thanks to the ability of the adequate dewatering, the substructure's water supply from the weather is nearly ended, the rigid layer can give more stability to the track structure, and the built in is easier, more cost efficient.

The authors still have to investigate its behavior in the railway track structure (especially the effect of the dynamical loads), but direction of the research can be assessed as good.

\subsubsection{Other technologies}

Few years ago, the Hungarian State Railways (MÁV) worked on a project, which wanted to develop a mobile screening technology. The base of this idea is the application of the amphibian mobile vehicles. Unfortunately, the project has been paused before time. 


\section{Summary}

In this paper the factors were showed, which can cause local substructure failures, and the applied diagnostic methods in Hungary. The railway protection layers were also showed which are capable for railway structures, and these were analyzed from the aspect of the improvement of the local failures. Summarized the material properties, the functions and the experiences, it was cleared that the often-used technologies do not give cost efficiently improving solution for local substructure problems.

To be able to solve this problem, the authors investigated the built-in eligibility of the mentioned new technologies. The injection technologies are not new solutions, there are many foreign and home experiences to show. Next to this technology, the cementitious geosynthetic composite mats could be potential key, because thanks to the materials properties and the experiences are deservedly thought it could give cost efficiently improving manner for the mentioned local problems. The authors are working to verify this.

\section{Acknowledgements}

The paper was written with the support of the project titled "Internationalisation, initiatives to establish a new source of researchers and graduates and development of knowledge and technological transfer as instruments of intelligent specialisations at Széchenyi István University" (project number: EFOP-3.6.1-16-2016-00017).

\section{References}

[1] MÁV, Railway construction and railway maintenance Vol. 1-2. Mezei, I., Horváth, F. (eds.), Magyar Államvasutak Rt., (1999), in Hungarian.

[2] Sz. Fischer, B. Eller et al., Railway construction, Universitas-Győr Nonprofit Kft., Györ, 2015.

URL

https://WwW.researchgate.net/publication/282246421_Railwa y_construction

[3] MÁV, D.11 Regulation: Design, construction, maintenance and renewing of railway substructures. Vol. 1., MÁV, Budapest, 2014, in Hungarian. 
[4] Sz. Fischer, Investigation of railway track geometry stabilization effects of geogrid layers under ballast bed PhD Thesis. Széchenyi István University, Győr, 2012, 148 p. in Hungarian.

doi: https://doi.org/10.13140/RG.2.1.4958.9921

[5] D. Larsson, A Study of the Track Degradation Process Related to Changes in Railway Traffic. PhD Thesis, Luleå University of Technology, Luleå, 2014. URL https://WwW.dissertations.se/dissertation/bec6dd1fd@/

[6] A. Nurmikolu, P. Kolisoja, Extruded polystyrene (XPS) foam frost insulation boards in railway structures. 16th International Conference on Soil Mechanics and Geotechnical Engineering, Osaka, 2005, pp. 1761-1764.

doi: https://doi.org/10.3233/978-1-61499-656-9-1761

[7] M. D. Roney, Heavy Hauling: A Worldwide Update and Highlights from IHHA2015. Heavy Haul Seminar WRI2016, 2016

URL ht tps://WWW. wheel-rail-seminars . com/archives/2016/hhpapers/HH\%2002\%20Highlights\%200f\%20IHHA2015. pdf

[8] D. Li, E. T. Selig, Evaluation of Railway Subgrade Problems. Transportation research Record 1489 (1995), pp. 17-25.

URL

http://onlinepubs. trb.org/Onlinepubs/trr/1995/1489/1489๑०3.pdf

[9] B. Eller, Sz. Fischer, Review of the modern ballasted railway tracks' substructure and further investigations, Nauka ta Progres Transportu 84 (6) (2019) pp. 72-85.

doi: https ://doi.org/10.15802/stp2019/195831

[10] S. Kaewunruen, C. Chiengson, Railway track inspection and maintenance priorities due to dynamic coupling effects of dipped rails and differential track settlements. Engineering Failure Analysis 93 (2018), pp. 157-171. doi: $10.1016 / j$. engfailanal.2018.07.009

[11] F. Horvát, E. Koch et al. Establishment of transitional sections between a bridge and railway track. Sínek Világa 60 (4-5) (2018). pp. 89-97, in Hungarian.

[12] E. Koch, Geotechnical impact assessment of bridge construction schedule, Sínek Világa 61 (3) (2019) pp. 9-17, in Hungarian. 
[13] E. T. Selig, J. M. Waters, Track geotechnology and substructure management, Thomas Telford Publications, London, 1994.

[14] B. Indraratna, W. Sahim et al., Advanced Rail Geotechnology - Ballasted Track, Professional book, Taylor \& Francis Group, London, 2011.

[15] E. T. Selig, D. D. Cantrell, Track Substructure Maintenace - From Theory to Practice. American Railway Engineering and Maintenance-of-Way Association Annual Conference, Chicago, Illinois, 2001

[16] B. Indraratna, J. Chu et al., Ground Improvement Case Histories: Compaction, Butterworth-Heinemann, Grouting and Geosynthetics, Oxford, 2015.

[17] B. Eller, Efficiency of the asphalt protection layer, cataloguing of its failures and technological suggestion for the renewing of the Dombóvár- Godisa railway track section, MSc Thesis, Széchenyi István University, 2016, in Hungarian

[18] N. Waldhör, As you make your bed so you must lie on it, Innorail Magazin 2 (1) (2015) pp. 48-52, in Hungarian.

[19] O. Szengofszky, How to terminate the velocity limits. Sínek Világa 56 (3) (2014) pp. 37-39, in Hungarian.

[20] V. Sárik, Examination of railway under-sleeper pads, Scientific Student Work, University of Technology and Economics of Budapest, 2014, in Hungarian.

[21] I. Simon, B. Eller, Mammals in the railway substructure, Sínek Világa 61 (2) (2019) pp. 25-28, in Hungarian.

[22] MÁV, D.5 Regulation: Track maintenance, MÁV, Budapest, 2017, in Hungarian.

[23] I. Zobory, Dynamics - measurement - qualification of the railway trackvehicle system, Közlekedéstudományi Szemle 65 (1) (2015) pp. 6-19, in Hungarian

[24] Cs. Ágh, Modern methods of examining railway tracks, Military Technical Bulletin 29 (2019) pp. 219-230, in Hungarian.

doi: $h$ ttps://doi.org/10.32562/mkk.2019.1.18 
[25] D. Krózser, Proposing the size limit of the standard deviation-based track geometry parameter, MSc Thesis, Széchenyi István University, 2019, in Hungarian.

[26] J. Hugenschmidt, Railway track inspection using GPR. Journal of Applied Geophysics 43 (2-4) (2000) pp. 147-155.

doi: https://doi.org/10.1016/s0926-9851(99)00054-3

[27] R. M. Narayanan, J. W. Jakub et al., Railroad track modulus estimation using ground penetrating radar measurements. NDT and E International 37 (2) (2004) pp. 141-151.

doi: https://doi.org/10.1016/j.ndteint.2003.05.003

[28] E. Gönczi, Application of radar detected geotextile in Hungarian. Sínek Világa 56 (3) (2014) pp. 21-24, in Hungarian.

[29] DB, Ril. 836: Earthwork and special geotechnic structures, design, construction and maintenance ("Erdbauwerke und sonstige geotechnische Bauwerke planen, bauen und instand halten"), in German.

URL https://dvlv.eu/interessante-links/db-dokumente/

[30] Plasser \& Theurer webpage [cited 2020-07-06].

URL https://WWw. plassertheurer.com/en/machines systems/formation-rehabilitation-pm-1000-urm.html

[31] S. Kaewunruen, Dynamic responses of railway bridge ends: A systems performance improvement by application of ballast glue/bond. Massachusetts Institute of Technology, 2014

URL http://works. bepress.com/sakdirat_kaewunruen/46/

[32] J. Szabó, Investigation and analysis of the behavior of ballasted railway superstructure stabilized with bed gluing technology on static and dynamic loads. PhD Thesis. University of Technology and Economics of Budapest, 2011, in Hungarian.

URL https://repozitorium.omikk. bme. hu/handle/10890/5597

[33] J. Rose, P. Teixeira et al., International design practices, applications, and performances of asphalt/bituminous railway trackbeds, GeoRail 2011 International, Paris, 2011.

URL

https://web.engr. uky.edu/ jrose/papers/GeoRail\%202011\%20In ternational.pdf 
[34]J. Rose, P. Teixeira et al., Utilization of asphalt/bituminous layers and coatings in railway trackbeds - a compendium of international applications, Joint Rail Conference, Urbana, Illinois, 2010

URL

https://web.engr.uky.edu/ jrose/papers/JRC_2010_Internatio nal.pdf

[35] Y. Tan, Research on Application of Cement Mortar Pile in Reinforcing Soft Foundation of High-speed Railway, Journal of Railway Engineering Society 2010 (10) (2010).

URL https://en.cnki.com.cn/Article_en/CJFDTotalTDGC201010006. htm

[36] S. Li, The application of cement injection pile in soft soil foundation reinforcement of existing railway line, Shanxi Architecture 2007 (8) 2007. URL https://en.cnki.com.cn/Article_en/CJFDTotalJZSX200708071.htm

[37]B. J. Warren, Field application of expanding rigid polyurethane stabilization of railway track substructure, MSc Thesis, University of Wisconsin-Madison, 2015.

URL $h$ ttps://minds.wisconsin. edu/handle/1793/72861

[38] A. Keene, J. M. Tinjum et al., Mechanical Properties of PolyurethaneStabilized Ballast, Geotechnical Engineering Journal of the SEAGS \& AGSSEA 45 (1) (2015) pp.67-73.

URL

https://WWw.researchgate.net/publication/273958170_Mechani cal_Properties_of_Polyurethane-Stabilized_Ballast

[39] T. Jirawattanasomkul, N. Kongwang et al., Finite element analysis of tensile and puncture behaviours of geosynthetic cementitious composite mat (GCCM). Composites Part B 154 (2018) pp. 33-42. doi: https ://doi .org/10.1016/j . compositesb. 2019.02.037

[40] P. Jongvivatsakul, T. Ramdit et al., Experimental investigation on mechanical properties of geosynthetic cementitious composite mat (GCCM). Construction and Building Materials 166 (2019) pp. 956-965. doi: $h$ ttps ://doi .org/10.1016/j . conbuildmat . 2018.01.185

[41] Concrete Canvas Ltd. [cited 2020-09-15].

URL https://wWw. concretecanvas.com 
[42] H. Li, H. Chen et al.,. Application design of concrete canvas (CC) in soil reinforced structure. Geotextiles and Geomembranes 44 (2016) pp.557-567. doi: https://doi.org/10.1016/j.geotexmem. 2016.03.003

[43] Trackway Trial: Melk, Austria (2011) Case Studies of CC. [cited 2020-0615].

URL https://WwW. concretecanvas.com

[44]B. Eller, Sz. Fischer, New possibilities of application of geosynthetic cementitious composite mats (GCCM) in railway substructure, Transport Science Conference, Győr, 2020, (accepted manuscript) in Hungarian. URL https://WWw.researchgate.net/publication/339366238_New_app lication_possibilities_of_geosynthetic_cementious_composit e_mat_layers_for_railway_substructure_in_Hungarian__Betonpaplan_reteg_ujfajta_alkalmazasi_lehetosegei_a_vasut i_alepitmenyben Creative Commons Attribution NonCommercial (CC BY-NC 4.0) license. 